\title{
THE ANALYSIS OF THE COMPREHENSIVE INSURANCE DEMAND FOR TURKEY USING UTILITY THEORY AND SYSTEM SIMULATION
}

\author{
Murat KIRKAĞAÇ ${ }^{1, *}$, Övgücan KARADAĞ ERDEMİR ${ }^{1}$, Yasemin GENÇTÜRK ${ }^{1}$ \\ ${ }^{1}$ Department of Actuarial Science, Faculty of Science, Hacettepe University, 06800, Ankara, Turkey
}

\begin{abstract}
In this study, the demand for comprehensive insurance is analysed using utility theory and system simulation. A simulation study is performed to assess the behaviour of individuals with different income levels for the demand of comprehensive insurance. Simulation assumptions and input-output variables are determined using the real data set from a Turkish insurance company and the report about the insurance activities in Turkey for year 2014. The effects of income level, expected claim severity and premium level on the demand for insurance are investigated. It is concluded that while an increase in income level and expected claim severity causes an increase in the demand, an increase in premium level causes a decrease in demand.
\end{abstract}

Key words: Utility function, Expected utility criterion, System simulation, The demand for comprehensive insurance

\section{INTRODUCTION}

In real life, people are confronted by several risks such as unemployment, fires and floods, hurricanes, earthquakes, motor vehicle accidents, changes in prices of assets affecting their finances, some of which can be insured [1]. Insurance products can generally be classified as life (life insurance, health insurance etc.) and non-life insurance (fire insurance, earthquake insurance, comprehensive insurance etc.). Compulsory traffic insurance and comprehensive insurance are the types of the automobile insurance. Although the compulsory traffic insurance is mandatory by law and protects the policyholder against losses arising due to bodily injury/death to a third party or any damage to property, the comprehensive insurance is optional and provides protection against any damage to the policyholder's car as a results of an accident, theft, fire, earthquake, etc. [2].

There are many factors affecting the demand for insurance. Dragos [3] investigated the effects of the income, education and urbanisation on life and non-life insurance demands in 17 emerging countries from Asia and Europe. Gümüş and Şerit [2] investigated the relation between socio-economic, demographic characteristics of car owners and their anxiety levels to take out a comprehensive insurance. Gümüş and Şerit [4] examined either the demographic characteristics or the level of anxiety was effective in taking out a fire insurance policy. Filiz [5] used the conjoint analysis to determine the criteria affecting the consumers' preferences to buy comprehensive insurance.

As there are many factors affecting the demand for an insurance, an individual faces with a decision making problem. Utility theory can be used while identifying and choosing alternatives based on the values and preferences. Schmidt [6] examined the insurance demand under the prospect theory in a simple model with fair insurance contracts. Garven [7] derived insurance demand equation for a riskaverse individual with logarithmic utility function. Nyman [8] reevaluated the conventional expected utility theory and its usefulness in explaining the demand for insurance. Cleeton and Zellner [9] investigated the relationship between the net demand for insurance and changes in the consumer's degree of risk aversion and concluded that the relationship depends upon the consumer's degree of risk aversion. When there is a risk or uncertainty, these must be incorporated into decision-making process and a 
system can be designed under some assumptions by means of simulation which generates following years' experience.

An individual faces with a decision making problem while deciding to buy an optional insurance one of which is comprehensive insurance. Expected utility criterion can be used to make this decision. In this study, a simulation is conducted to determine the demand for comprehensive insurance using a utility function.

This paper is organized as follows: utility theory and types of utility functions are explained in Section 2.1 and system simulation, especially Monte Carlo method, is reviewed in Section 2.2. A simulation study along with its results and some scenarios are given in Section 3 and concluding remarks are provided in Section 4.

\section{METHODS}

\subsection{Utility Theory}

Utility theory has been developed to provide insights into decision making despite uncertainty [10]. Utility function $u(x)$ can be described as a function measuring the value or utility that an individual attaches to monetary amount $x$. It should satisfy the conditions $u^{\prime}(x)>0$ and $u^{\prime \prime}(x)<0$ [11]. Widely used utility functions can be given as follows:

- Exponential utility function : $u(x)=-\exp (\beta x)$ for $\beta>0$

- Quadratic utility function: $u(x)=x-\beta x^{2}$ where $x<\frac{1}{2 \beta}$ and $\beta>0$

- Logarithmic utility function: $u(x)=\beta \log (x)$ for $x>0$ and $\beta>0$

- Fractional power utility function: $u(x)=x^{\beta}$ where $x>0$ and $0<\beta>1$ [12].

There is a strong relationship between insurance and the utility theory. The utility theory can explain why people agree to pay premiums for insurance. Decision maker can decide between two options using the expected utility criterion. According to this criterion, the option whose expected value of utility is higher than the other one is selected. The expected utility criterion can also be used whether to buy or not to buy an insurance policy.

Let $W$ be income, $P$ be premium and $X$ be claim severity. Using expected utility criterion, the following decision can be made:

- If $u(W-P)>E[u(W-x)]$, decision maker prefers insurance.

- If $u(W-P)=E[u(W-x)]$, decision maker is indifferent.

- If $u(W-P)<E[u(W-x)]$, decision maker prefers to pay the claim.

\subsection{System Simulation}

Decision makers implementing the solution in a system approach need to know the system and model concepts. The general definition of the system is a construction consisting of components between which a relationships exists and which affect each other mutually. Model is defined as the relationships between systems that are determined by physical sizes and verbal or mathematical expressions. The inputs of a mathematical model are decision variable and system parameters; the outputs of a mathematical model are system performance index and state variables [13].

In order to comprehend the workings of a real-life system, a mathematical model should be established for the system, which sums up the necessary parts of the system in mathematical language, involving variables, parameters, formulas, probability distributions, relations, diagrams, etc. [14]. 
Simulation is the imitation of the operation of a real-world process or system over time [15]. If solution of the model may not be obtained by analytical methods and if the model of the system examined has a stochastic structure; in other words, if the system has variables containing uncertainty, solution could be analysed with Monte Carlo simulation which involves samples of observations selected randomly according to the distribution required [16]. Because of the fact that there is an uncertainty for the risks occurring in future, Monte Carlo technique is also utilized in insurance.

A general system simulation algorithm can be given as follows [13]:

- Step 1 Identify the problem

- Step 2 Investigate available data sources and determine data requirements

- Step 3 Collect necessary data, estimate the parameters of the simulation model

- Step 4 Determine decision variables depending on scenarios and state variables

- Step 5 Write the computer programme of the system simulation model

- Step 6 Test the validity of the simulation model. If it is not valid, turn back previous steps

- Step 7 Interpret the results. If they are not satisfying, turn back to the previous steps.

\section{SIMULATION STUDY}

An individual can decide whether to buy an insurance or not by taking into account the utility of buying an insurance policy. There are some factors affecting the demand for insurance. Here, it is considered that income level, level of claim severity to be paid when an accident occur and premium to be paid when an insurance policy is taken out are important factors affecting the demand.

According to Turkish Statistical Institute (TUIK), 6.2\% of Turkish population has annual income of 4515 TL (Group 1) while 10.9\% possesses annual income of approximately 7894 TL (Group 2). The other three groups are categorised as follows: $15.3 \%$ having an average of $11157 \mathrm{TL}$ annual income (Group 3), 21.7\% having 15792 TL of annual income (Group 4) and the last group which consist of $45.9 \%$ of the population who earns approximately 33417 TL yearly (Group 5). The Group 3 is taken as Base Group. As there is not available data to investigate the income distribution, in this study it is assumed that for these five income groups average yearly income has uniform distribution with approximately the averages mentioned above and the simulation is conducted separately for these risk classes.

In actuarial science, heavy-tail distributions such as lognormal, gamma, Pareto and Weibull are widely used to model insurance claim severity data [17], [18]. In order to determine the claim severity distribution of comprehensive insurance, data taken from a Turkish insurance company for year 2014 is analysed. Both the p-value for Kolmogorov-Smirnov test statistic 0.09278 and p-value for Chi-square test statistic 0.01965 are larger than significance level 0.01 , it is concluded that lognormal fits the data quite well.

As the data used belongs to a Turkish insurance company and as our aim is to investigate the demand for comprehensive insurance for whole Turkey, the average claim severity value in the report about the insurance activities in Turkey for year 2014 taken from Republic of Turkey Prime Ministry Undersecretariat of Treasury is used to determine the parameters of lognormal distribution. The average claim severity in Turkey for 2014 is 600.59 TL. Utilizing this average claim severity for the Base Group, the parameters of lognormal distribution are determined as $\mu=6.138$ and $\sigma^{2}=0.721^{2}$. The parameters of the claim severity distribution for other groups given in Table 1 are determined assuming that as income increases average claim severity increases and vice versa.

For these five groups, gross premium $\mathrm{P}$ is calculated according to the expected value premium principle. That's, 
Kırkağaç et al. / Anadolu Univ. J. of Sci. and Technology A-Appl. Sci. and Eng. 18(1)-2017

$$
P=(1+\alpha) E(X), \quad \alpha>0
$$

where $\alpha$ is loading factor and $E(X)$ is the expected claim severity [6].

In insurance, risk classes are constituted in order to charge a fair premium. In comprehensive insurance, the insurance amount of the car is an important factor taking into account while making a risk classification. As it is thought that people with lower income probably have a car with a lower insurance amount. Therefore, each income group is divided into three subgroups considered as risk classes. Loading factors for these subgroups are taken as $0.001,0.005$ and 0.01 respectively.

In this study, fractional power utility function is used while making the decision about taking out a comprehensive insurance, The $\beta$ parameter of this utility function is taken as 0.01 .

Under these assumptions, the steps of the algorithm can be written as follows:

- Step 1 Generate income (W) from Uniform(a,b)

- Step 2 Generate claim severity (X) from Lognormal $\left(\mu, \sigma^{2}\right)$

- Step 3 Calculate the premium using $P_{i}=\left(1+\alpha_{i}\right) E(X)$

- Step 4 Calculate the expected utilities using the fractional power utility function $u(x)=x^{\beta}$

- Step 5 Compare the expected utilities

- Step 6 Count the number of trials where decision maker prefers insurance

- Step 7 Calculate the mean and variance of these trials.

A simulation study with 1000 trials has been conducted and the results are summarized in Table 1 .

Table 1. Assumptions and results of simulation

\begin{tabular}{|lcccc|}
\hline Group & Income(TL) & $\begin{array}{c}\text { Claim severity } \\
\text { dist. }\end{array}$ & Premium & $\begin{array}{c}\text { Result of } \\
\text { simulation }\end{array}$ \\
\hline Group1 & & & $3000<\mathrm{W}<4000 \rightarrow P_{1}$ & mean=0.5445 \\
$(\% 6.2$ of Turkey) & $\mathrm{U}(3000,6000)$ & $\mathrm{LN}(4.891,0.908)$ & $\begin{array}{c}4000<\mathrm{W}<5000 \rightarrow P_{2} \\
5000<\mathrm{W}<6000 \rightarrow P_{3}\end{array}$ & variance=0.2481 \\
\hline Group2 & & & $6000<\mathrm{W}<7500 \rightarrow P_{1}$ & mean=0.5715 \\
(\%10.9 of Turkey) & $\mathrm{U}(6000,10000)$ & $\mathrm{LN}(5.655,0.822)$ & $7500<\mathrm{W}<9000 \rightarrow P_{2}$ & variance=0.2450 \\
& & & $9000<\mathrm{W}<10000 \rightarrow P_{3}$ & \\
\hline Group3 & & & $10000<\mathrm{W}<11500 \rightarrow P_{1}$ & mean=0.6121 \\
$(\% 15.3$ of Turkey) & $\mathrm{U}(10000,14000)$ & $\mathrm{LN}(6.138,0.721)$ & $11500<\mathrm{W}<13000 \rightarrow P_{2}$ & variance $=0.2376$ \\
& & & $13000<\mathrm{W}<14000 \rightarrow P_{3}$ & \\
\hline Group4 & & $14000<\mathrm{W}<15000 \rightarrow P_{1}$ & mean=0.6498 \\
$(\% 21.7$ of Turkey) & $\mathrm{U}(14000,18000)$ & $\mathrm{LN}(6.501,0.607)$ & $15000<\mathrm{W}<17000 \rightarrow P_{2}$ & variance=0.2276 \\
& & & $17000<\mathrm{W}<18000 \rightarrow P_{3}$ & \\
\hline Group5 & & & $18000<\mathrm{W}<29000 \rightarrow P_{1}$ & mean=0.6807 \\
$(\% 45.9$ of Turkey) & $\mathrm{U}(18000,52000)$ & $\mathrm{LN}(6.959,0.513)$ & $29000<\mathrm{W}<40000 \rightarrow P_{2}$ & variance $=0.2174$ \\
& & & $40000<\mathrm{W}<52000 \rightarrow P_{3}$ & \\
\hline
\end{tabular}


In Table 1, the mean shows the average ratio value of the number of trials in which decision maker prefers insurance to the total number of trials. In other words, the mean illustrates the demand for comprehensive insurance of the population. As an example, the mean 0.6121 for Base Group shows that the utility of taking out the comprehensive insurance is higher for approximately 612 individuals out of 1000. Therefore, 612 individuals should prefer taking up the comprehensive insurance. As seen from Table 1, Group 1 has the smallest mean value of 0.5445. The mean increases as the income level increases and it reaches to 0.6807 for the highest income group. As expected, people with high income level are much more eager to take up insurance than those with low income level. It is also seen that variance of the trials decreases as income level increases.

Using the results given in Table 1, the mean for the whole population of Turkey in year 2014 is calculated as 0.6431 by taking the percentages of income level as weights. Therefore, it can be concluded that $64.31 \%$ of the whole population should prefer to take up comprehensive insurance.

Some scenarios are generated to investigate the effects of inputs on the results. The sensitivity of the results to the changes in the expected claim severity is analysed by taking the income and premium loading factor constant. For this purpose, Group 3 in Table 1 is considered as the base scenario and five scenarios are generated by changing the parameters of lognormal distribution which leads to changes in expected claim severity. In Scenarios 1 and 2, the expected claim severity is lower and in Scenarios 4 and 5, the expected claim severity is higher than that of base scenario. Simulation results for these scenarios are given in Table 2.

Table 2. The effects of claim severity on demand for insurance

\begin{tabular}{|ccc|}
\hline Scenarios & $\begin{array}{c}\text { Expectation of } \\
\text { claim severity }\end{array}$ & $\begin{array}{c}\text { Result of } \\
\text { simulation }\end{array}$ \\
\hline Scenario1 & $\mathrm{E}(\mathrm{X})=200.98$ & $\begin{array}{c}\text { mean }=0.1113 \\
\text { variance }=0.0989\end{array}$ \\
\hline Scenario2 & $\mathrm{E}(\mathrm{X})=400.55$ & $\begin{array}{c}\text { mean }=0.3764 \\
\text { variance }=0.2349\end{array}$ \\
\hline Scenario3 & $\mathrm{E}(\mathrm{X})=600.59$ & mean $=0.6121$ \\
variance $=0.2381$
\end{tabular}

According to Table 2, it can be concluded that people are more willing to buy insurance as the expected claim severity increases and vice versa.

To investigate the effect of the premium charged on the results, the parameters of the claim severity distribution and income level are kept constant. The loading factors $\alpha_{1}, \alpha_{2}$ and $\alpha_{3}$ are taken as 0.001 , 0.005 and 0.01 respectively in the base scenario. To examine the effects of the premium levels, the loading factors are determined as in Table 3. In Scenarios 1 and 2, the loading factors are lower and in Scenarios 4 and 5, the loading factors are higher than that of base scenario. 
Kırkağaç et al. / Anadolu Univ. J. of Sci. and Technology A-Appl. Sci. and Eng. 18(1)-2017

Table 3. The effects of premium on demand

\begin{tabular}{|c|c|c|}
\hline Scenarios & Premium loading factors & $\begin{array}{c}\begin{array}{c}\text { Result of } \\
\text { simulation }\end{array} \\
\end{array}$ \\
\hline Scenario1 & $\alpha_{1}=0.00001, \alpha_{2}=0.00005, \alpha_{3}=0.00010$ & $\begin{array}{c}\text { mean }=0.6187 \\
\text { variance }=0.2361\end{array}$ \\
\hline Scenario2 & $\alpha_{1}=0.00010, \alpha_{2}=0.00050, \alpha_{3}=0.00100$ & $\begin{array}{c}\text { mean }=0.6147 \\
\text { variance }=0.2369\end{array}$ \\
\hline $\begin{array}{c}\text { Scenario3 } \\
\text { (Base Scenario) }\end{array}$ & $\alpha_{1}=0.00100, \alpha_{2}=0.00500, \alpha_{3}=0.01000$ & $\begin{array}{c}\text { mean }=0.6121 \\
\text { variance }=0.2376\end{array}$ \\
\hline Scenario4 & $\alpha_{1}=0.01000, \alpha_{2}=0.05000, \alpha_{3}=0.10000$ & $\begin{array}{c}\text { mean }=0.5793 \\
\text { variance }=0.2437\end{array}$ \\
\hline Scenario5 & $\alpha_{1}=0.10000, \alpha_{2}=0.50000, \alpha_{3}=1.00000$ & $\begin{array}{c}\text { mean }=0.4221 \\
\text { variance }=0.2489\end{array}$ \\
\hline
\end{tabular}

As seen from Table 3, the more the premium is charged the less the demand for comprehensive insurance is. As the loading factors in base scenario are chosen quite small, the changes of the mean in Scenario 1 and 2 compared to the base scenario could be negligible.

The effect of the $\beta$ parameter of utility function is also investigated. The results are not given here as it does not affect the means considerably.

\section{CONCLUSION}

In this paper, utility theory and system simulation are incorporated to analyse the demand for comprehensive insurance. Under some assumptions, a simulation study is conducted for five income groups. It is unsurprisingly concluded that as the income level increases, the demand for insurance increases. In order to see the effects of claim severity and premium on the demand, five different scenarios are designed. The average ratio of taking up insurance increases as the expected claim severity increases. It is also found out that the increase in premium decreases the demand for insurance.

\section{REFERENCES}

[1] Guiso L, Jappelli T. Background uncertainty and the demand for insurance against insurable risks. Centre for studies in economics and finance 1998; working paper no 2.

[2] Gümüş FM, Şerit K. Is there any relationship between making motor insurance with persons' demographics features and otherwise with persons' anxiety level?. AIBU Sosyal Bilimler Enstitüsü Dergisi 2015; 15 (1): 111-141.

[3] Dragos SL. Life and non-life insurance demand: the different effects of influence factors in emerging countries from Europe and Asia. Economic Research-Ekonomska Istrazivanja 2014; 27 (1): 169-180.

[4] Gümüş FM, Şerit K. Is there any relationship between making fire insurance with persons' demographics features and otherwise with persons' anxiety level?. Journal of Business Research Turk, 2014; 6 (4): 191-210.

[5] Filiz Z, Şengöz M. Kasko sigortası tercihinin konjoint analizi ile incelenmesi. "İş Güç" Industrial relations and human redources journal 2010; 12 (1): 107-121. 
Kırkağaç et al. / Anadolu Univ. J. of Sci. and Technology A-Appl. Sci. and Eng. 18 (1) - 2017

[6] Bitler MP, Schmidt L. Utilization of infertility treatments: the effects of insurance mandates Demography 2012; 49 (1): 125-149.

[7] Garven JR. The demand for insurance, 2006.

[8] Nyman JA. The demand for insurance: expected utility theory from a gain perspective. University of Minnesota 2001; 1-31.

[9] Cleeton DL, Zellner BB. Income, risk aversion, and the demand for insurance. Southern Economic Journal 1993; 60 (1): 146-156.

[10] Bowers NL, Gerber HU, Hickman JC, Jones DA, Nesbitt CJ. Actuarial mathematics, 1997.

[11] Gerber HU, Pafum, G. Utility functions: from risk theory to finance, North American Actuarial 1998; 2 (3): 74-91.

[12] Dickson DCM. Insurance risk and ruin. Cambridge University Press, 2005.

[13] Erdemir C, Kadılar C. Benzetim tekniklerine giriş. Hacettepe Üniversitesi Yayınları, 2003.

[14] Kroese DP, Taimre T, Botev ZI. Handbook of monte carlo methods. John Wiley \& Sons, 2013.

[15] Banks J, Carson J, Nelson B, Nicol D. Discrete-event system simulation. Prentice Hall, 2001.

[16] Tse YK. Nonlife actuarial models: theory, methods and evaluation. Cambridge University Press, 2009.

[17] Achieng OM. No I. Actuarial modelling for insurance claim severity in motor comprehensive policy using industrial statistical distributions. International Congress of Actuaries; 2010; Cape Town: pp. 712.

[18] Kaarik M, Umbleja M. Estimation of claim size distributions in Estonian traffic insurance. Proceedings of the international conference on applied computing conference. World Scientific and Engineering Academy and Society (WSEAS); 2010; pp. 28-32.

[19] Bulut B, Erdemir C. Kalın kuyruklu hasar modellerinde iflas olasılı̆̆ının benzetim yöntemi ile hesaplanmas1-otomobil sigortas1 örneği. Journal of Statisticians 2012; 5: 1-13. 